\title{
Who is deprived? Who feels deprived? \\ Labor Deprivation, Youth and Gender in Morocco
}

\author{
Umar Serajuddin and Paolo Verme*
}

\begin{abstract}
The paper provides a methodology to better understand how objective conditions of deprivation are translated into subjective feelings of deprivation using a strand of the recent literature on relative deprivation. In line with Akerlof and Kranton (2000) and Goldin (2006), we postulate that gender norms are associated with identity and the reference group, the group of peers that people use to compare themselves with. We find that the reference group plays a pivotal role in understanding how feelings of labor deprivation are generated and this can explain the apparent mismatch between objective conditions of deprivation and subjective feelings of deprivation related to joblessness among young men and women. It can also potentially help governments design public policies that address objective conditions of deprivation, such as unemployment, with a better understanding of subjective implications.
\end{abstract}

JEL codes: D30, D63, I31

Keywords: Labor participation, reference groups, relative deprivation, subjective deprivation, Morocco

* The World Bank. Corresponding Author: pverme@worldbank.org .

** The findings, interpretations, and conclusions expressed in this paper are entirely those of the authors. They do not necessarily represent the views of the World Bank, its Executive Directors, or the countries they represent. The authors are grateful to Bernard Funck, Gabriela Inchauste, Branko Milanovic, Devesh Roy, Tara Vishwanath, participants at the World Bank conference on Equity held in Washington DC in June 2012, and participants at a seminar held in Rabat at the High Commission for Planning in May 2012 for very useful comments on previous versions of the paper. All remaining errors are the sole responsibility of the authors. 


\section{Introduction}

Very few people could have predicted the Arab spring and the revolutions that are still unfolding in the Arab world. But for those who travelled through Arab countries in recent years the sense of malaise felt by the general public, in particular the youth, was evident and visible in phenomena such as the emigration of the skilled and the unskilled - explained by the lack of work opportunities at home - and the degree of marginalization from economic activities of the youth who did not emigrate abroad, especially young women. In spite of improved economic conditions and growth, the Arab populace enjoyed little gains in employment or labor force participation. The labor force participation of women in the MiddleEast and North-Africa region is the lowest across all the regions of the world. In some countries as many as half of the youth aged 15 to 29 are out of school and out of work.

Participating in the labor market is important to people beyond the economic rewards that they may derive from employment. It provides a sense of purpose and the feeling of contributing to society that has a meaning in itself. Conversely, lack of employment can provide a sense of emptiness and exclusion that can lead to anxiety and depression. The social psychology and labor economics literature largely agree on this point and it is not surprising that employment features among the top policy priorities of any government (see, e.g., Clark and Oswald 1994).

Yet, individuals are not identical in how they may perceive a condition of joblessness and it is not uncommon to see very large differences in attitudes towards employment across social groups. For example, urban residents are typically louder in voicing their labor market complaints than rural residents despite the lower living conditions in rural areas, and in many societies labor market expectations across genders are different, resulting in different emotional attitudes towards employment. How can we reconcile the objective status of labor deprivation with subjective feelings of labor deprivation across social groups?

This paper uses the concept of relative deprivation to better understand how objective conditions of labor deprivation can be transformed into subjective feelings of labor deprivation for different social groups. We focus on youth and gender using a unique household and youth survey administered in Morocco in 2010 and we propose a new measure of relative labor deprivation that takes into account both objective and subjective aspects of deprivation.

The concept of relative deprivation is not new. Both Adam Smith in the Wealth of Nations (1776) and Karl Marx in Wage, Labor and Capital (1847) delved extensively into the idea that people compare themselves with their peers and neighbors rather than with the whole society. In the last century, Stouffer et al. (1949) and Runciman (1966) contributed to formalize the concept of relative deprivation by introducing the notion of reference groups and by discussing the importance of the reference group in generating feelings of deprivation. Economics has approached the question of relative deprivation and reference groups in more recent times with the introduction of the first quantitative measure of relative deprivation developed by Yitzhaki in 1979, and today there are a range of measures of relative deprivation that can be readily used for analyses (Hey and Lambert, 1980, Bossert and D'Ambrosio, 2006, Chakravarty et al. 2005, Chakravarty, 2007). In particular, recent research has shown how quantitative measures of relative deprivation can be adapted to incorporate self-selection mechanisms of 
the reference groups (Verme and Izem, 2008, Silber and Verme, 2012), an issue particularly relevant if we want to better understand how feelings of deprivation can be generated among marginalized groups in society.

The reference group is one of the key elements in understanding individual identity and self-assessment. In their seminal paper on economics and identity Akerlof and Kranton (2000) show how identity - 'a person's sense of self - can be used to explain human behavior that would otherwise conflict with standard utility theory. As stated by the authors, "Identity can account for many phenomena that current economics cannot well explain. It can comfortably resolve, for example, why some women oppose "women's rights," as seen in microcosm when Betty Friedan was ostracized by fellow suburban housewives for writing The Feminine Mystique. Other problems such as ethnic and racial conflict, discrimination, intractable labor disputes, and separatist politics all invite an identity-based analysis." (p. 715). In this framework, identity is based on social categories, and in turn, social categories can be defined along personal characteristics such as gender, age, wealth, ethnicity, or location. Individuals belong to sets of social categories that delineate their own identity and these categories imply standard 'prescriptions' or behavioral norms. Therefore, identity is defined by the reference group - the group of people that individuals feel they belong to - and the reference group influences the expected behavior.

Akerlof and Kranton (2000) note how important this aspect is in understanding gender differences in labor force participation, the main focus of this paper. If society views women's role as "housewives" and men's role as "breadwinner", women would be hesitant to join the labor force in greater numbers as that could "evoke anxiety and discomfort in oneself" while males would see female participation in the labor force as a "threat" to their own male identity. To the degree these factors influence women's participation decisions, they can help to explain why female labor force participation rates remain so low and at the same time why many women may not feel as distressed by this outcome: "Similarly women's assumed lower desire for labor force participation (as in Mincer and Polachek \{1974\}, Bulow and Summers \{1986\}, and Lazear and Rosen \{1990\}) can be understood as the result of their identity as homemakers." (Akerlof and Kranton, 2000, p. 732). Claudia Goldin, a leading authority in female participation rates in the U.S., described the post-1968 growth in female participation in the US as a "revolution" (Goldin, 2006) ${ }^{1}$ and pinpointed two major factors behind this revolution: "expanded horizons" with women expectations increasing quickly and influencing a shift in educational choices, and "altered identities" with women behaving more independently from their partners. Changes in the reference group are closely intertwined with changes in expectations and identity and these are important factors to consider for the measurement of relative deprivation.

Based on these premises, this paper will draw on a recent literature that explores how the inclusion of the reference group into measures of relative deprivation can help to explain the apparent mismatch between objective statuses of labor deprivation and subjective perceptions of these same statuses. This is an important issue to understand in designing economic policies that aim to integrate women in the labor market. For this purpose we devise a measure of relative labor deprivation following a two-steps model initially suggested by Verme (2010). This method builds on a recent literature that gives more emphasis to the question of the reference group and its role in determining feelings of deprivation. In particular, the

1 See also Goldin (1990). 
methodology allows for integrating a mechanism for the selection of the reference group in measures of relative deprivation and making different assumptions on how individuals select the reference group.

We find that our measure of relative deprivation can provide very different results depending on whether the reference group is gender specific or not. When we assume that women and men compare themselves with both genders, we find women to be more relatively deprived than men, which is what measures of objective deprivation (such as unemployment or labor force participation) would suggest. If, instead, women and men limit their own reference group to their own gender, we find that men are more relatively deprived than women. This last result conforms to the general observation that women tend to complain less than men about their labor market status despite higher objective deprivation levels. This result is also strongly supported by recent evidence from a qualitative study in Morocco (World Bank 2012) that found both genders arguing that men suffer much more than women from labor deprivation.

Furthermore, we find our measure of relative labor deprivation to be strongly associated with subjective responses to questions about social status and emigration. For example, the satisfaction levels reported by youth regarding their opportunities to improve their social status in the future are inversely related to the paper's estimated levels of relative labor deprivation. And, for men, relative labor deprivation is positively associated with the wish to emigrate abroad when the reference group is constituted by other men. These findings underline the importance of the reference group in transforming objective conditions of deprivation into subjective feelings of deprivation, they are relevant for other countries in the region and call for further research in this area.

The paper is organized as follows. In section two we provide an overview of youth and gender in the Moroccan labor market. In section three, we present the relative deprivation framework that we intend to apply in the paper, while section four describes the data we use. Section five illustrates the results and section six concludes.

\section{Youth and gender in the Moroccan labor market}

During the last decade, Morocco enjoyed sustained economic growth with an average annual growth rate of about 5 percent, almost twice its average growth rate during the 1990s. Growth has been associated with positive developments in a wide range of areas. The poverty rate, for example, declined from 16.3 percent in 1999 to 8.9 percent in 2007 (Douidich and Ezzrari, 2010), a rather remarkable achievement in such a short period of time. Substantial gains have been achieved in education, with broad access to basic education and improvements in the number of people receiving higher levels of education. And health indicators such as infant and maternal mortality show consistent positive trends over the past thirty years. As a result, the Human Development Index (HDI) for Morocco increased from 0.507 to 0.582, although the country retains a low rank in the global HDI classification.

Yet, comparable positive trends are not visible in labor market indicators. Recent economic growth has not been sufficient to accommodate the growing working age population. According to the official estimates of the Haut Commissariat au Plan (HCP 2012), in 2010 slightly less than half of the population (49.6 percent of those aged 15 and over) participated in the labor market, which constitutes one of the lowest activity rates in the region. In fact, during the decade following 1999, labor force participation 
rates fell by about 5 percentage points. While inactivity in the labor market is high, unemployment is also high at 9.1 percent, despite a five percentage points decline between 1999 and 2010. In essence, the encouraging gains in unemployment may be mostly explained by the losses in labor force participation with people migrating from the pool of the unemployed to the pool of the economically inactive.

The labor market situation is particularly grim for the youth and women. Young people aged 15 to 29 years represent almost a third of the population, and among the very young (ages 15-24), unemployment is almost three and a half times as high as compared to the labor force as a whole. Among those who are employed, a majority faces exclusion from the formal labor market and many are underemployed. Women - older as well as the young - face particularly strong economic exclusion. The labor force participation rate of women in 2009 was a third of that of men (25.8 percent as compared to 75.3 percent, HCP 2009), one of the lowest female participation rates in the world. These two marginalized groups constitute the majority of the Moroccan population.

The increased exclusion of youth and women during the growth period of the last decade is puzzling and disquieting. It is puzzling because economic growth was expected to pull some of the inactive into the labor force while it didn't. It is disquieting because the 2011 Arab spring in countries such as Tunisia and Egypt has been largely fuelled by young people, men and women alike, and many commentators associated these events with persistent lack of labor market opportunities for the youth.

While improvements in growth and labor demand remain compelling prerequisites for improving labor force participation overall, changes in perceptions and expectations can play an important role in terms of female labor force participation. A recent World Bank (2012) study conducted focus group interviews with young people of diverse backgrounds across Morocco and found that an overwhelming majority of both female and male interviewees believed men to be relatively more disadvantaged than women in the domestic labor market. This can appear somewhat counterintuitive since women participate in far lower numbers than men to the labor market and, among those who do participate in the labor force, unemployment levels among women tend to be higher. However, focus group participants held the view that for men employment was an economic and social imperative, while for women it was more of a choice. Hence, the self-esteem of males was tied more closely to their employment status than that of females. The World Bank (2012) study summarizes focus group participants' viewpoints as follows: "Young men are thus seen as suffering most from adverse labor market conditions, not because the objective situation is more adverse for them, but rather, because it is much more socially detrimental for men to be excluded from the labor market. Although it may be highly desirable for women to work, it was not a social requirement: a woman without work would still be respectable and able to find satisfaction in life primarily in marriage and children." (p.41)

Quantitative data are also indicative of strong gender norms. For example, the time use module in the Morocco Household and Youth Survey (MHYS) 2009-10 suggests that young women on average do far more of the housework than do men. In fact, employed women spend much more time in household chores than non-employed men as shown in Table 1. Akerlof and Kranton (2000) argue that such patterns, seen in wealthier developed countries as well, results not from women's comparative advantage in home production but rather from the importance of gender identity. 


\section{[Table 1 here]}

Quantitative evidence from the MHYS further indicates that most young men and women hold the belief ('prescription') that women should perform more household tasks than men, as documented in Table 2. Women presently do more work inside the home and less work outside as compared to men. Interestingly, the "how would you like it to be" scenario is not much different across men and women. Further, while men are open to women working more outside of the house, they also want them to continue their housework routines. Women also reveal that they would like to engage in more of home production than men do, while simultaneously aspiring to work outside the home. These responses reveal strong gender norms related to the labor market participation on the part of both men and women. Such gender norms are not unique to the Arab world and have been documented for other countries, including the U.S. and Europe (Mincer and Polachek 1974, Bulow and Summers 1986, Lazear and Rosen 1990, Akerlof and Kranton 2000).

These findings provide a strong rationale for considering reference groups across gender lines when it comes to evaluating one's relative status in the labor space. If women and men derive their level of deprivation from the comparison within gender rather than between genders, feelings of deprivation would depend on such comparison. This should not be seen as a value judgment but simply as a fact that needs to be taken into account if one wishes to explain sentiments of labor deprivation.

\section{[Table 2 here]}

\section{From income inequality to labor deprivation}

In economics, the concepts of inequality and relative deprivation are very close, both conceptually and mathematically. In this section, we show how one can navigate between these two concepts and construct a measure of relative labor deprivation that can effectively be used to better understand feelings of deprivation as opposed to the objective condition of deprivation and gain some useful insights for the design of public policies that target specifically marginalized groups.

Let $y$ be a measure of welfare and $i$ or $j$ denote individuals with $i, j=1,2 \ldots n$ and $n \in N$. Let also $Y$ be a distribution of welfare values with $Y=\left(y_{1}, y_{2}, \ldots, y_{n}\right)$ and $Y \in R^{n}$. Then, one of the possible formulations of the Gini index is

$$
G=\frac{1}{\mu n^{2}} \sum_{i=1}^{n} \sum_{j>i}\left(y_{j}-y_{i}\right)
$$

with $\mu=\frac{1}{n} \sum_{i=1}^{n} y_{i}$ and income sorted in descending order of magnitude. In this particular formulation of the Gini index, inequality is seen as the sum of the sums of the welfare distances between each individual in the population and all richer individuals.

The concept of relative deprivation can be expressed in very similar terms. In his theory of social justice, Runciman (1966) was the first to propose a definition and a methodology to measure relative deprivation defined as a sentiment that emerges from inter-personal comparisons. More specifically, a person who is 
relatively deprived is a person who: 1) Does not have X; 2) Sees some other person or persons as having X; 3) Wants X; and 4) Sees it as feasible to have X. Based on this notion, Yitzhaki (1979) proposed to measure individual relative deprivation $\left(R D_{i}\right)$ by taking the average distances between each individual incomes and the income of all richer individuals so that

$$
R D_{i}=\frac{1}{n} \sum_{j>i}\left(y_{j}-y_{i}\right)
$$

In this context, the individual feeling of relative deprivation is measured in terms of average welfare distances so that the further the individual's welfare is from all richer individuals the more deprived this individual will feel. Relative deprivation for a society $R D$ is then simply the aggregation of the individual relative deprivation scores across the population:

$$
R D=\frac{1}{n^{2}} \sum_{i=1}^{n} \sum_{j>i}\left(y_{j}-y_{i}\right)
$$

which Yitzhaki (1979) noted as being equal to the absolute Gini index (the Gini multiplied by the mean). This measure is scale variant but it can be easily made scale invariant by dividing it by the mean so that we return to the Gini index formulated in (1). Therefore, if we use the formulation of the Gini index proposed in (1), relative deprivation and the Gini inequality measure are the same, both at the individual and at the societal levels. The difference is simply the interpretation of these measures. Relative deprivation at the individual level has a clear interpretation - being the individual sense of deprivation while individual inequality is a meaningless concept.

The Yitzhaki measure of relative deprivation was the first relative deprivation measure introduced in economics and paved the way for a rich literature that explored various aspects of the concept of relative deprivation as well as various forms of indexes (Hey and Lambert, 1980; Berrebi and Silber, 1985; Chakravarty, 1995 and 1997; Bossert, D’Ambrosio and Peragine, 2007). As in the Yitzhaki seminal paper, this literature considered the entire population or the population of richer individuals as the reference group for individuals. In other words, the underlying assumption is that individuals are able to observe all other individuals in society, compare all these other individuals with themselves and derive from this comparison a sense of relative deprivation.

In recent years, the question of reference group or the question of which other people matter when individuals compare themselves with others has attracted substantial attention. As already noted by Smith, Marx, Stouffer, and Runciman, it is recognized that people cannot observe all other individuals in any given society and that inter-personal comparisons are built around specific reference groups. We tend to compare ourselves with a restricted number of people who belong to the same self-constructed and imaginary group we think we belong to. For example, we may not feel deprived comparing our income with that of Bill Gates but we may feel very deprived if a colleague at work earns marginally more than we do. Therefore, the question of the selection of the reference group is an important one when it comes to measuring relative deprivation (e.g., Clark and Senik 2010).

A more recent literature on relative deprivation has attempted to include mechanisms of self-selection of the reference group into measures of relative deprivation. Verme and Izem (2008), for example, have 
argued that people compare themselves with their likes and tend to self-select the reference group on the basis of personal characteristics such as age, gender, education, language or ethnic group. In such framework, relative deprivation can be measured by simply taking the difference between the Yitzhaki measure calculated on incomes and the same measure calculated on expected incomes where expected incomes are estimated based on a set of personal characteristics thought to be used by most people for selecting the reference group.

Similarly, Silber and Verme (2010) have proposed a relative deprivation measure that exploits expected incomes and breaks relative deprivation into two components. The first component is called structural mobility and measures the difference between the inequality (Gini index) of the distribution of the actual incomes and that of the expected incomes. The second component is called exchange mobility and measures the amount of re-ranking that takes place when one compares the position of the individuals in the distribution of the actual and predicted incomes. Total deprivation in the population is therefore a function of these two elements. The concept of relative deprivation is no longer a measure of welfare distances between different people but becomes a measure of distances between one's own income status and the income status that one would expect given one's own personal characteristics.

This last concept of relative deprivation has recently been extended to the labor market by Verme (2010). Joblessness or lack of labor, can naturally be seen as a condition of labor deprivation. However, the joblessness status cannot automatically be considered as a measure of the "feeling" of labor deprivation for at least two reasons. First, joblessness can be a consequence of different situations. A person could be jobless by choice (technically belonging to the economically inactive), because of lack of the necessary skills (labor market mismatch) or because of other causes such as discrimination. Each of these situations would potentially imply different degrees of feelings of deprivation and a measure that aims at capturing individual deprivation should be able to discriminate between these different conditions. And second, measuring relative deprivation implies quantifying feelings of deprivation for each individual and joblessness or unemployment status is a binary 0-1 variable that cannot serve this purpose.

These two issues can be overcome by following the two-steps approach proposed by Verme (2010) in the labor space. Expected joblessness or expected unemployment is first estimated with a probit or logit model based on a number of personal characteristics believed to be used by people for inter-personal comparisons. The labor status predicted in this way is then considered as a measure of the labor status that individuals would expect to have if all people with the same characteristics were treated equally. Subsequently, by taking the difference between actual labor status and expected labor status (the residuals of the prediction equation) we can measure the degree of individual labor deprivation.

Formally, let $g_{i}$ be a binary variable that splits the labor force into two groups with $g_{i}=1$ if the individual belongs to a "good" labor market status and $g_{i}=0$ if the individual belongs to a "bad" labor market status. Let also $X_{i}$ be a vector of personal characteristics thought to be used by individuals to selfselect the reference group. We can then regress $X_{i}$ on $g_{i}$ so that $g_{i}=\alpha+\beta X_{i}+\epsilon$ and then estimate the expected labor status $\hat{g}_{i}$ so that the difference $d_{i}$ can be considered as a measure of relative labor deprivation:

$$
d_{i}=\hat{g}_{i}-g_{i}
$$

with $-1 \leq d_{i} \leq 1 ; 0 \leq \hat{g}_{i} \leq 1$ and $g_{i}=\{0,1\}$ 
Positive values of the individual labor deprivation score $\left(d_{i}\right)$ indicate a condition of deprivation, being the actual labor status lower than the expected labor status. Vice-versa, negative values indicate a condition of satisfaction with the actual status being better than the expected status. ${ }^{2}$

This simple measure of deprivation can be conveniently used as a measure of welfare in a Yitzhaki type of relative deprivation index where the individual deprivation scores are used in place of the welfare measure. We can then define the individual Relative Labor Deprivation $\left(R L D_{i}\right)$ as

$$
\begin{gathered}
\qquad L D_{i}=\frac{1}{\mu n} \sum_{J=1}^{i}\left(d_{i}^{\prime}-d_{j}^{\prime}\right) \\
\text { where } d^{\prime}=\frac{(1+d)-\min (1+d)}{\max (1+d)-\min (1+d)}{ }^{3}
\end{gathered}
$$

The interpretation of (4) is that individuals take into account not only the distance between their own (normalized) actual labor status and their expected labor status $\left(d_{i}^{\prime}\right)$ but they also consider the gap between their own distance and the distance of other less deprived individuals in society. Therefore, we are introducing the concept of "envy" in the measure of relative deprivation and consider that individual relative deprivation can be affected by how other people in society feel about their own relative deprivation. It is also important to note that we are standardizing the measure by the mean. This is different from the Yitzhaki measure of relative deprivation and from Verme (2010) and makes our measure scale invariant, which is useful if we wish to compare relative deprivation across groups that might have very different means in observed welfare such as urban and rural areas.

The individual values in equation (4) can then be additively aggregated to measure labor relative deprivation at the societal level as follows

$$
R L D=\frac{1}{\mu n^{2}} \sum_{i=1}^{n} \sum_{J=1}^{i}\left(d_{i}^{\prime}-d_{j}^{\prime}\right)
$$

Mathematically, the less diverse a society is in terms of personal characteristics $\left(X_{i}\right)$, the closer actual $\left(g_{i}\right)$ and expected $\left(\hat{g}_{i}\right)$ labor status, the smaller individual labor deprivation $\left(R L D_{i}\right)$, the smaller inequality across individual labor deprivation scores and the smaller societal labor deprivation $(R L D)$ will be.

Such measure of relative labor deprivation has the additional advantage that can be additively decomposed by population sub-groups as follows:

\footnotetext{
${ }^{2}$ Note that if group A has all jobs $\left(g_{i}=1\right)$, group B has no jobs $\left(g_{i}=0\right)$ and we make joint estimations for both in step 1 of the model (we assume that both groups compare themselves with both groups), the deprivation score (the residual, $d_{i}=\hat{g}_{i}-g_{i}$ ) will be always positive for group B and always negative for group A. This will make group B worse off than group A because all members of group B will show higher deprivation than any member of group A. In this case, the prediction would comply with the expectation that group B should feel more deprived than group A. However, if group A has all jobs and group B has no jobs, we cannot make separate estimations for each group in step 1 of the model because there would be no variation in the dependent variable for any of the two groups. Therefore, our measure cannot be estimated with the assumption of separate reference groups if the two groups observed are perfectly split along the two categories of the dependent variable in step 1 of the model.

${ }^{3}$ This is a standard normalization of the individual score between zero and one. The normalization is necessary to avoid negative values in the Yitzhaki-type of index.
} 


$$
R L D=\frac{1}{\mu n^{2}} \sum_{g=1}^{m} \sum_{i=1}^{n} R L D_{i}
$$

Where $g=\{1,2 \ldots, m\}=$ Number of groups. ${ }^{4}$

The $R L D$ decomposition is an exact decomposition by population sub-groups. As it is well known in the welfare literature, the Gini coefficient can be decomposed into within and between components (Bourguignon 1979, Shorrocks 1984) but cannot be decomposed additively into population sub-groups. The relative labor deprivation measure proposed, which utilizes the Gini formula, can instead be decomposed by population sub-groups simply because the individual scores of relative labor deprivation have a straightforward interpretation and are scale and population invariant.

There is an additional advantage of the relative labor deprivation measure proposed. When we estimate the expected labor status, we have a choice of making estimates using the whole population or sub-groups of the population. For example, we may argue that women tend to compare themselves with women only rather than with both women and men together. In this case, the estimation of the expected labor status can be done separately for women and men and the expected labor status can then be re-aggregated at the societal level. This last procedure provides different results and can potentially offer some insights into why, for example, women may feel less relatively deprived than we would expect given their labor status and their own personal characteristics. This seems an important advantage of the measure proposed in a country like Morocco and, more generally, in North-Africa and the Middle-East where the gender divide in the labor market is very important and still little understood.

\section{Data}

This paper uses data from the Morocco Household and Youth Survey (MHYS) of 2009-2010, a household survey designed to study economic and social exclusion of the young population in Morocco. It is a nationally representative survey of 2,000 households, 1,216 urban and 784 rural, including modules on demographic and educational characteristics, economic activities, household assets and expenditure, the ability to cope with shocks, use of social assistance, and migration behavior. In addition, the MHYS administered a separate instrument with additional questions on various aspects of employment and civic participation of 2,883 young individuals aged 15 to 29 (representing about 90 percent of the youth in the surveyed households).

The survey intended to reach approximately 3,000 young people aged between 15 to 29 years. Data from the General Census of Population and Habitat (GCPH) of 2004, suggested that there were about 1.5 young people per Moroccan household aged between 15 and 29. This implied that about 2,000 households would need to be surveyed to reach 3,000 young people. The sample of 2,000 households was selected from a master sample prepared following the GCPH of 2004. The country was divided into several Primary Sampling Units (PSU) each comprising about 600 households. The master sample represented 20 percent of the country and consisted of 1,848 PSUs (1,124 urban and 724 rural). These

\footnotetext{
${ }^{4}$ The implicit assumption of an additive and linear aggregation of individual deprivation is that individuals are identical in feelings and behavior as in standard utility theory.
} 
PSUs were established following a set of criteria reflecting differences between urban and rural areas, and boundaries dividing entities such as regions, districts, rural communities, cities and municipalities. There were two stratification criteria for urban PSUs (city size and type of habitat) and one stratification criterion for rural PSUs (degree of isolation expressed by the distance from a paved road).

A total of 125 PSUs - 76 urban and 49 rural - were finally extracted from the 1,848 PSUs in the master sample. The PSUs were further split into 12 Secondary Sampling Units (SSU) of about 50 households each. One SSU was randomly selected from each PSU. The random sampling of SSUs was conducted by experts from the Department of Statistics of Morocco's High Commission for the Plan, who were also responsible for creating the master sample. A census of households was then conducted by the survey teams in each of the 125 SSUs. From this list, 16 households were randomly selected within each SSU, leading to a total sample of 2000 households.

For the analysis of relative income and labor deprivation the sample is limited to those individuals aged between 15 and 64 who are not enrolled in school. This restricts the sample to 6,451 individuals $-3,339$ females and 3,112 males. In the last stage, we further restrict the sample to the 2,128 youth (aged 15-29) $-1,085$ females and 973 males - who are not enrolled in school.

\section{Results}

\subsection{Relative deprivation in the income space}

Following from section 3, in this section we start by illustrating the relation between the gini inequality measure and the relative deprivation index proposed by Yitzhaki (1979) applying these measures to income, using household expenditures per capita as its proxy. The expenditure module of the MHYS was used to construct a household level expenditure aggregate, which was adjusted for cost of living

differences across rural and urban areas. ${ }^{5}$ We then apply our labor deprivation measure to expenditure per capita and show how this measure can be used in the income space. In the next section, we turn to the labor space.

In Table 3, we report the Gini index together with the mean and the relative deprivation measure proposed by Yitzhaki (1979). As shown by Yitzhaki, the relative deprivation measure is equivalent to the absolute Gini index, which is the Gini multiplied by the mean. This implies that relative deprivation is affected by either a change in inequality or a change in mean, or both. For example, if we compare the scores for females and males we find inequality among males to be slightly lower and the mean expenditure to be barely higher. This results in an overall relative deprivation index being very similar across women and men.

\section{[Table 3 here]}

\footnotetext{
${ }^{5}$ To adjust nominal expenditure across rural and urban households in the absence of CPI data that covers prices in rural areas or information on unit values from the household survey, we take a simpler approach. We use the ratio of the official urban and rural poverty line of 2007 as reported by the HCP to adjust nominal expenditures across rural and urban households. Urban prices are assumed to be 7.4 percent higher than rural prices (the ratio of the urban and rural poverty line or 3834 / 3569).
} 
However, as shown in section 3, the Yitzhaki relative deprivation measure is not scale invariant and the observed difference across genders is a combination of inequality effects and mean effects. Moreover, the reference group in the Yitzhaki measure is defined as all richer individuals and there is no in-built mechanism for the selection of the reference group. The labor deprivation measure proposed in Section 3 allows for the selection of the reference group and can also be applied to the income space, simply by estimating expected incomes instead of expected labor participation in the first step of the model.

Table 4 provides a first illustration of our index in the income space using alternative reference groups. When we experiment with a joint reference group, i.e., when women and men compare themselves with both genders, we find women to be less relatively deprived than men while the opposite is true if we constrain the sample to the youth population. These differences are however very small. When we change the reference group and estimate our first step of the model within each gender, we find that for the whole population males are now more deprived than females; this ranking is maintained for the youth population as well. Although, as argued in the introduction, it is not income that appears to drive discontent, this first simple exercise shows that the gender ranking of relative deprivation can change if we change the reference group. We also find that relative deprivation at the societal level is lower if the reference group is within genders as the between group inequality does not play a role.

\section{[Table 4 here]}

\subsection{Relative deprivation in labor space}

In this section, we shift from relative deprivation in the income space to relative deprivation in the labor space. In doing so, we also turn from the household dimension to the individual dimension of relative deprivation. This will allow us to be more precise on assumptions related to the relevant reference group for individuals and for inter-personal comparisons.

Table 5 reports descriptive statistics of labor market outcomes as well as the characteristics of individuals used in the estimations of relative labor deprivation in the paper. The statistics is limited to those individuals who can feasibly be in the labor market, i.e., to working age individuals who are not enrolled in school. In general, employment levels are very low in the sample with only 40 percent of the working age population being employed. Among young people aged 15-29, employment levels are considerably lower than the working age population as a whole, with only one in three people being employed. The unemployment rate among the young population is almost twice as high as compared with the entire working age population.

The disparity in outcomes between men and women is also telling. An estimated 11 percent of working age women are employed as compared to 71 percent for men, the latter itself being low by international standards. The gender dimension in unemployment is significant as well. The unemployment rate among women aged 15-64 years is twice as high as that of men (23 percent versus 12 percent). Education levels among women appear lower as well with the exception of tertiary education, although the tertiary education population is a small fraction of the overall population (less than five percent for both women and men). Thus, from the descriptive statistics, it appears that the youth are objectively deprived compared to the non-youth, and that women are objectively deprived compared to men. 


\section{[Table 5 here]}

To construct the labor group variable $\left(g_{j}\right)$ used for the first step of the two-steps model proposed, the labor force was split into two categories: individuals who were employed at the time of the survey were classified to be in the 'good' category $\left(g_{i}=1\right)$, while those who were unemployed or were out of the labor force altogether were classified to be in the 'bad' category $\left(g_{i}=0\right)$. This choice is justified by the fact that in a country with a large informal sector, a large rural population and a history of long-term unemployment, unemployment alone is not a good indicator of labor market malaise. This is also witnessed by the fact that in Morocco the reduction in the unemployment rate of the last ten years has been accompanied by a reduction in labor force participation.

To estimate the predicted values of the good state (i.e., employment) we used education levels, marital status, age and location related variables. We are therefore assuming that these are the main variables that individuals can observe in other people and can use to compare their own labor market status with the status of others. This is evidently a normative and also a conservative choice which may be seen as a common minimum denominator for all individuals. It is also a standard approach to the choice of variables for the selection of the reference group in papers that attempted similar approaches (see Van Praag et al 1979, Woittiez and Kapteyn, 1998, Clark and Senik, 2010). We may argue that each individual has a different reference group and that many more factors come into play when people compare themselves with others. However, it is also true that certain criteria for the selection of the reference group are rather standard and apply to most people and that it would be arguably hard to construct individualized preference models. By being conservative, we hope to capture the standard and essential comparison criteria used by most people.

Table 6 reports results from the probit regressions used to estimate the probability of individuals being employed, i.e., being in the 'good' labor market state. Four different models are estimated: with all individuals (including and excluding the gender variable - columns 1 and 2), with males only (col. 3) and with females only (col. 4). Here we see how the researcher can make different assumptions about the reference group. If we want to compare the relative deprivation of men and women, we can either assume that both genders compare themselves with both genders, or alternatively that men compare themselves with men and women compare themselves with women. In the first case, the first-step estimation is carried out jointly for men and women as in column 2 . In the second case, the first-step estimation is carried out separately for men and women as in columns 3 and 4.

A first insight into the gender divide can be gathered by comparing columns 1 and 2 . The gender variable is clearly very significant in explaining labor status and its inclusion increases the pseudo-R squared very significantly - from 0.07 to 0.33 - indicating that gender is the major predictor of employment among the variables considered. In the two-steps model proposed, however, we have to remove the gender variable if our objective is to compare men and women. This is what we did in columns 2-4. Here we can see that by splitting the sample across genders - the pseudo-R squared increases for both genders from, 0.07 to 0.15 . We can also see how differently the same variables perform for men and women. For example, having primary education as compared to no education does not improve a female's employment status but improves the male's. Being married improves the likelihood of a good labor market status for men but reduces the likelihood for women. And urban women do not seem to have a comparative advantage in accessing a good labor status as compared to rural women while urban men do worse than rural men. 
Therefore, changing assumptions about the reference group by shifting from population to within-group reference group can make a very substantial difference in the first-step estimation and, consequently, in assessing relative labor deprivation.

\section{[Table 6 here]}

The probit estimates from models 2, 3, and 4 are then used to construct individual relative labor deprivation indices as described in equation (4). Aggregating these individual indices we can obtain the societal relative deprivation measure as in equation (5). Table 7 reports the relative labor deprivation (RLD) values for different sub-populations based on different specifications of the reference group.

When all individuals constitute the reference group, we find women to have higher levels of relative deprivation than men. This can be seen by decomposing the societal value by gender, which shows that total female RLD is almost three times as that of males for the society as a whole. This is expected as women in Morocco are also considerably more excluded from the labor market in an objective or absolute sense. If women compare their situation with better-off men, they would naturally feel more deprived than men. If we focus on youth only, the gender gap is reduced but the ranking is the same with females being more deprived than males.

By contrast, if the relevant reference populations are along gender lines, the situation is reversed. First, overall societal relative deprivation falls in comparison to the level when the entire population is the reference group. This is due to the fact that the between male-female difference does not play a role when the reference group is gender specific. Moreover, in this new gender specific scenario, the estimates for male relative deprivation are twice as high as that for females if we consider the whole society. If we focus on the youth, the reversal of gender positions also applies and the gender gap increases. Now young males appear to be much more deprived than young females.

\section{[Table 7 here]}

Qualitative insights from a recent World Bank (2012) study can explain and validate these findings. As mentioned earlier, this study found that an overwhelming majority of both female and male interviewees believed men to be relatively more disadvantaged than women in the domestic labor market and this was motivated by gender specific norms, precisely as postulated in the Akerlof and Kranton (2000) study on identity.

The construction of an individual measure of relative labor deprivation also allows for the use of this measure in distributional analyses by constructing Pen's parades, Cumulative Distribution Functions (CDFs) or Lorenz curves. As an example, in Figure 1 (left hand panel) we plotted the Lorenz curves using the two different assumptions of joint and separate reference groups. The results illustrate graphically what we have learned so far. If the reference group is gender specific, as opposed to being relative to everyone in society, the feelings of deprivation would be lower and the societal RLD is lower. Indeed, if we estimate RLD within each gender (right hand panel, Figure 1), we find that RLD for men is much more pronounced than RLD for women, as we noted when we looked at the indexes.

In essence, by changing the reference group, we find that the gender ranking is reversed and, rather than reflecting a condition of objective deprivation, it reflects a condition of subjective deprivation. 


\section{[Figure 1 here]}

\subsection{How good is the indicator of relative labor deprivation?}

The concept of relative labor deprivation developed in this paper is a statistical construct that claims the ability to capture subjective feelings of deprivation. In this section, we attempt to determine whether the measure of relative deprivation proposed is effectively related to subjective feelings of satisfaction or deprivation as reported by respondents in the MHYS.

For a sub-sample of the population (2,128 young individuals aged 15 to 29 who are currently out of school) we can examine the relation between relative labor deprivation and subjective wellbeing. The survey we use includes questions on self-reported satisfaction with different aspects of life. It also includes a question on the intention to migrate, a variable we presume to signal discontent with the current situation, especially with labor market status. We should expect a good measure of deprivation to be inversely related with measures of subjective satisfaction as found for example in D'Ambrosio and Frick (2007) and in Silber and Verme (2010, 2012).

Table 8 shows the results of an ordered probit regression of young people (aged 15-29) where the dependent variable is satisfaction with opportunities to improve social status in the future. The satisfaction variable takes four values, ranging from very unsatisfied $=1$ to very satisfied $=4$. We consider different models. Model 1 does not include the indicator of relative labor deprivation, rather it includes the actual employment status of individuals. Conversely, models 2-4 include our relative labor deprivation variable but exclude employment. Model 2 estimates the influence of relative deprivation on satisfaction levels when the reference group is assumed to be the entire population. Models 3 and 4 include the measure of relative labor deprivation when the reference group is segmented along gender lines as we did in the previous section.

As expected, employment status matters for satisfaction with opportunities to improve social status in the future. Employed people evidently see better prospects for the future as compared with the non-employed. More importantly from the standpoint of this paper, in all specifications (models 2, 3, and 4) satisfaction with opportunities to improve social status in the future is negatively and significantly associated with relative labor deprivation. This relation is significant at the one percent level in all specifications and becomes stronger when the reference group is split along gender lines, a fact that supports our hypothesis that males and females tend to select the reference group within their own gender.

\section{[Table 8 here]}

Education and marriage are factors associated with greater satisfaction with the potential to improve social status as it is also known in the happiness literature. Higher levels of education and marriage are typically associated with greater life satisfaction and our results are in line with such findings. In models 1 and 2, it is also apparent that young males have lower levels of satisfaction than young women, which is 
consistent with our finding that relative labor deprivation is higher for young males as compared to young females. ${ }^{6}$

Next, in table 9 we present a probit regression of determinants concerning young people's wish to migrate abroad. The dependent variable takes a value of one if a youth wishes to migrate and zero if not.

\section{[Table 9 here]}

We would expect youth who wish to migrate abroad to be unsatisfied with domestic labor market conditions and suffer from stronger feelings of deprivation. Interestingly, employment status in itself is not a significant predictor of the wish to migrate. However, relative labor deprivation among men is strongly associated with the wish to migrate abroad (model 4). This variable is not significant for women (model 3), and not significant when we consider the reference group to be the entire population (model 2). This confirms once more the higher discontent of men with their current situation and the importance of using separate reference groups when we study deprivation along gender lines.

We also estimated the models presented in tables 8 and 9 controlling for household economic status proxied by household per capita expenditure or the asset index. While satisfaction levels are positively associated with economic status, the signs of the coefficients of relative deprivation do not change in either case suggesting that the strength of the relation between our measure of relative labor deprivation and indicators of subjective satisfaction holds across the distribution of welfare.

As a final test of our relative labor deprivation measure, we also regressed the measure against subjective feelings of satisfaction that are not expected to be strongly associated with labor deprivation. While our measure of relative labor deprivation is a good predictor of individual optimism/pessimism about the future, we find that it is not significantly associated with non-economic subjective wellbeing measures such as satisfaction with voice in society or with satisfaction with participation in the life of the community. We can therefore conclude that the measure of relative labor deprivation proposed in this paper is a fairly good predictor of subjective feelings of deprivation as reported by respondents.

\section{Conclusions}

The paper highlighted the issue of the difference between objective and subjective deprivation, which seems particularly important in the light of the recent revolutions that characterize the Arab spring. It also suggested that the role of the reference group and of the selection of the reference group is pivotal in understanding the difference between objective and subjective deprivation. On these bases, the paper has proposed a measure of relative labor deprivation that could potentially help to better capture "feelings" of deprivation and help explain social outcomes in Morocco (and potentially in other Arab countries as well).

The measure proposed has several advantages. It builds in a mechanism for the selection of the reference group, it allows for making different assumptions about the reference group and it can be decomposed

\footnotetext{
${ }^{6}$ Specifying the above regression as a probit with the dependent variable being defined as satisfied/dissatisfied (1/0) yields results that are similar in interpretation.
} 
into population sub-groups, other than by between and within groups. Moreover, the individual scores of this measure can be used as a variable for econometric or distributional analyses.

The paper shows how, by using the relative labor deprivation measure proposed, we can gain much better insights into other important divides such as the gender divide. In particular, we found that when we change assumptions about the reference group, we can capture real feelings of deprivation much better. This would explain, for example, why women who are more objectively deprived than men in the labor market tend to feel less deprived.

We then tested the validity of these findings by studying the association between our measure of relative labor deprivation and subjective responses to questions about social status and migration. We found a strong association between our measure and these variables whereas we found no association between our measure and subjective variables that are not expected to be associated with labor deprivation such as satisfaction with voice in society or with satisfaction with participation in the life of the community. Moreover, we also found that our findings strongly match the findings of a study conducted with focus groups in Morocco.

These are encouraging results in the context of there being very few instruments to understand the relation between objective and subjective deprivation. The shock generated by the Arab spring among observers worldwide has underlined how inadequate our understanding of this relation is. This paper has provided a first set of tools to better understand how objective deprivation may turn into 'feelings' of deprivation.

These findings have important policy implications. Policy makers should have an interest in understanding the gap between objective and subjective deprivation. In theory, policy should be guided by objective conditions of deprivation, not by subjective feelings. Economic policies should be concerned about reducing unemployment rather than distributing jobs to louder groups who may in fact be less objectively deprived. In practice, however, politicians or governments understandably respond to manifested social discontent and they frequently succumb to the temptation of implementing short-term policies. It is well known, for example, that the Arab spring has resulted in a wave of populist measures such as increases in public employment and public wages. These policies, however, are often not directed toward groups that face poorer outcomes such as women or the youth. Our methodology highlights the objective-subjective deprivation divide. An understanding of this divide can help policy makers make better choices by designing policies that are responsive to the objective conditions of deprivation as well as being cognizant of peoples' sentiments.

More importantly, the findings of this paper suggest that changes in gender norms are associated with changes in the reference group, identity and expectations that can have a lasting effect on labor market statistics. This is neither surprising nor new. It is a very well documented phenomenon that characterized labor markets in the US after the 1968 youth movement. According to the US Bureau of Labor Statistics: "Women's labor force participation, which was at a rate of 33.9 percent in 1950, increased significantly during the 1970s and 1980s, climbing to 57.5 percent in 1990. ${ }^{7}$ Claudia Goldin, an authority in female participation rates in the US, described this phenomenon as a "revolution" (Goldin, 2006) and pinpointed two major factors behind this revolution; "expanded horizons" with women expectations increasing quickly and determining a shift in educational choices and "altered identities" with women behaving more

\footnotetext{
${ }^{7}$ http://www.bls.gov/opub/ted/2007/jan/wk2/art03.htm
} 
independently from their partners and taking their own labor market decisions. As for the 1968 revolution, the 2011 youth movement in the Arab world may well contribute to change gender norms.

\section{References}

Akerlof, G. A., and Kranton, R.E. 2000. "Economics and Identity." Quarterly Journal of Economics, 115 (3): 715-753.

Berrebi, Z. M. and J. Silber. 1985. "Income Inequality Indices and Deprivation: A Generalization." Quarterly Journal of Economics, 100 (3): 807-810.

Bossert, W. and C. D’Ambrosio. 2006. "Reference Groups and Individual Deprivation.” Economics Letters, 90 (3): 421-426.

Bossert, W., C. D’Ambrosio, and V. Peragine. 2007. "Deprivation and Social Exclusion." Economica, 74 (296) :777-803.

Bourguignon, F. 1979. "Decomposable Income Inequality Measures." Econometrica, 47 (4), 901-902.

Bulow, J.I. and L.H. Summers. 1986. "A Theory of Dual Labor Markets with Application to Industrial Policy, Discrimination, and Keynesian Unemployment." Journal of Labor Economics, 4(3): 376-415.

Chakravarty, S. R. 1997. "Relative Deprivation and Satisfaction Orderings." Keio Economic Studies, 34 (2): 17-31.

Chakravarty, S. R., N. Chattopadhyay, and A. Majumder. 1995. "Income Inequality and Relative Deprivation." Keio Economic Studies, 32 (1): 1-15.

Clark, A. and C. Senik. 2010. "Who Compares to Whom? The Anatomy of Income Comparisons in Europe.” Economic Journal, 120 (544): 573-594.

Clark, A. E. and A. J. Oswald. 1994. "Unhappiness and Unemployment." Economic Journal, 104 (424): 648-659.

D'Ambrosio, C and J. R. Frick. 2007. "Income Satisfaction and Relative Deprivation: An Empirical Link.” Social Indicators Research, 81:497-519.

Douidich, M. and A. Ezzrari. 2010. "Dynamique de la pauvreté 1985-07." High Commission for the Plan, Morocco (http://www.omdh.hcp.ma/Dynamique-de-la-pauvrete-1985-07_a184.html).

Elbers, C., J. O. Lanjouw and P. Lanjouw. 2005. "Imputed Welfare Estimates in Regression Analysis." Journal of Economic Geography, 5: 101-118.

Fernández, R. 2007. "Culture as Learning: The Evolution of Female Labor Force Participation over a Century.” NBER Working Paper, No. 13373.

Goldin, C. 1990. Understanding the Gender Gap: An Economic History of American Women. Oxford University Press, New York.

Goldin, C. 2006. "The Quiet Revolution That Transformed Women's Employment, Education and Family.” American Economic Review, 96 (2): 1-21.

Hey, J. D. and P. J. Lambert. 1980. "Relative Deprivation and the Gini Coefficient: Comment." Quarterly Journal of Economics, 95 (3): 567-573. 
HCP (2012) Activite, Emploi et Chomage, various years, High Commission for the Plan, Morocco http://www.hcp.ma/downloads/

High Commission for the Plan, Morocco

Lazaer, E.P. and S. Rosen. 1990. "Male-Female Wage Differentials in Job Ladders. Journal of Labor Economics, 8(1): S106-S123.

Marx, K., 1847. "Wage Labour and Capital," translated in 1891 by Frederick Engels, in chapter "Relation of Wage-Labour to Capital." Available at: http://www.marxists.org/archive/marx/works/1847/wagelabour/ch06.htm

Mincer, J. and S. Polachek. 1974. "Family Investments in Human Capital: Earnings of Women." Journal of Political Economy, 82(2): S76-S108.

Runciman, W. G. 1966. Relative Deprivation and Social Justice. Routledge and Kegan Paul, London.

Sen, A. 2006. Identity and Violence: The Illusion of Destiny (Issues of Our Time). W.W. Norton, New York.

Shorrocks, A. F. 1984. "Inequality Decomposition by Population Subgroups." Econometrica, 52(6): 1369-1385.

Silber, J. and P. Verme. 2010. "Distributional change, reference groups, and the measurement of relative deprivation," in John A. Bishop (ed.), Studies in Applied Welfare Analysis: Papers from the Third ECINEQ Meeting (Research on Economic Inequality, Volume 18), Emerald Group Publishing Limited, Chapter 9, pp.197-217

Silber, J. and P. Verme. 2012. "Relative Deprivation, Reference Groups and the Assessment of the Standard of Living." Economic Systems, 36 (1): 31-45.

Stouffer, S.A., E.A. Suchman, L.C. DeVinney, S.A. Star, and R.A. Williams. 1949. The American Soldier (1): Adjustment during Army Life. Princeton University Press.

Van Praag, B., A. Kapteyn, and F. Van Herwaarden. 1979. "The Definition and Measurement of Social Reference Spaces." The Netherlands Journal of Sociology, 15: 13-25.

Verme, P. 2010. "Relative Labour Deprivation and Internal Migration in Turkey." Journal of Economic Inequality, 8 (4): 391-408.

Verme, P. and R. Izem. 2008. "Relative Deprivation with Imperfect Information.” Economics Bulletin, 4 (7): $1-9$.

World Bank. 2012. "Kingdom of Morocco: Promoting Youth Opportunities and Participation." Report No. 68731-MOR. Middle East and North Africa Region, Sustainable Development Department, The World Bank.

World Bank. 2010. "Kingdom of Morocco; Poverty in Rural Areas: What We Know, What We Don't Know, What We Should Know." Unpublished Manuscript. Middle East and North Africa Region, MNSED, The World Bank.

Wodon, Q. and S. Yitzhaki. 2009. "May growth lead to higher deprivation despite higher satisfaction?" Policy Research Working Paper Series 4921, The World Bank. 
Woittiez, I. and A. Kapteyn. 1998. "Social Interactions and Habit Formation in a Model of Female Labour Supply." Journal of Public Economics, 70(2): 185-205.

Yitzhaki, S. 1979. "Relative Deprivation and the Gini Coefficient." Quarterly Journal of Economics, 93 (2): 321-324. 
Table 1: Share of time (\%) spent on household chores and child care (for 15-29 year olds, as a fraction of their non-sleep / non-personal time)

\begin{tabular}{lll|lll}
\hline & Female & Male & & Female & Male \\
Education & & & Household Wealth & \\
No education & 34.2 & 1.1 & Bottom Quintile & 31.4 & 1.4 \\
Primary & 27.0 & 1.2 & 2nd Quintile & 24.5 & 1.1 \\
Secondary & 16.7 & 0.9 & 3rd Quintile & 22.7 & 1.2 \\
Post-Secondary & 10.6 & 1.1 & 4th Quintile & 21.1 & 0.8 \\
Marital Status & 0.0 & 0.0 & Top Quintile & 19.4 & 0.7 \\
Not married & 18.5 & 1.1 & Location & & \\
Married & 36.1 & 0.7 & Rural & 28.3 & 0.9 \\
Employment Status & 0.0 & 0.0 & Urban & 19.7 & 1.2 \\
Not employed & 24.7 & 1.3 & All & 23.7 & \\
Employed & 12.8 & 0.6 & &
\end{tabular}

Source: MHYS 2009-2010 
Table 2: Youth responses to present and desired future situation of certain tasks in the household

\begin{tabular}{|c|c|c|c|c|c|c|c|c|}
\hline \multirow{3}{*}{$\begin{array}{l}\text { How it is currently in the } \\
\text { household? }\end{array}$} & \multicolumn{4}{|c|}{ Male responses (\%) } & \multicolumn{4}{|c|}{ Female responses $(\%)$} \\
\hline & \multirow[t]{2}{*}{$\begin{array}{l}\text { Female } \\
\text { s do } \\
\text { more }\end{array}$} & \multirow[t]{2}{*}{$\begin{array}{l}\text { Males } \\
\text { do } \\
\text { more }\end{array}$} & \multirow[t]{2}{*}{$\begin{array}{l}\text { Both } \\
\text { do the } \\
\text { same }\end{array}$} & \multirow[t]{2}{*}{$\begin{array}{l}\text { Not } \\
\text { applic } \\
\text { a-ble }\end{array}$} & \multirow[t]{2}{*}{$\begin{array}{l}\text { Female } \\
\text { s do } \\
\text { more }\end{array}$} & \multirow[t]{2}{*}{$\begin{array}{l}\text { Male } \\
\text { s do } \\
\text { more }\end{array}$} & \multirow[t]{2}{*}{$\begin{array}{l}\text { Both do } \\
\text { the } \\
\text { same }\end{array}$} & \multirow[t]{2}{*}{$\begin{array}{l}\text { Not } \\
\text { applica- } \\
\text { ble }\end{array}$} \\
\hline & & & & & & & & \\
\hline Preparing meals & 88.3 & 2.3 & 5.2 & 4.2 & 95.2 & - & 2.6 & 2.2 \\
\hline $\begin{array}{l}\text { Doing house cleaning } \\
\text { work }\end{array}$ & 88.4 & 2.4 & 5.1 & 4.2 & 95.0 & 0.1 & 2.8 & 2.2 \\
\hline Working outside the house & 3.5 & 68.4 & 22.3 & 5.8 & 5.5 & 61.5 & $\begin{array}{l}26 . \\
2\end{array}$ & 6.9 \\
\hline $\begin{array}{l}\text { Caring for } \\
\text { (children, } \\
\text { handicapped) }\end{array}$ & 57.5 & 2.8 & 8.4 & 31.2 & 68.3 & 1.0 & 6.4 & 24.3 \\
\hline \multicolumn{9}{|c|}{ How would you like it to be in the future? } \\
\hline Preparing meals & 77.6 & 1.8 & 18.9 & 1.7 & 81.8 & 0.5 & $\begin{array}{l}16 . \\
0\end{array}$ & 1.6 \\
\hline $\begin{array}{l}\text { Doing house cleaning } \\
\text { work }\end{array}$ & 80.6 & 2.1 & 15.7 & 1.7 & 82.4 & 0.9 & $\begin{array}{l}15 . \\
0\end{array}$ & 1.7 \\
\hline Working outside the house & 1.9 & 48.0 & 48.6 & 1.4 & 3.1 & 35.9 & $\begin{array}{l}59 . \\
0\end{array}$ & 2.1 \\
\hline $\begin{array}{l}\text { Caring for } \\
\text { (children, } \\
\text { handicapped) }\end{array}$ & 69.4 & 2.6 & 16.8 & 11.2 & 71.2 & 1.4 & $\begin{array}{l}19 . \\
1\end{array}$ & 8.3 \\
\hline
\end{tabular}


Table 3: Inequality and relative deprivation (per capita expenditure)

\begin{tabular}{lccc}
\hline & $\begin{array}{c}(1) \\
\text { Full Sample }\end{array}$ & $\begin{array}{c}(2) \\
\text { Female }\end{array}$ & $\begin{array}{c}(3) \\
\text { Male }\end{array}$ \\
\hline Gini & 0.316 & 0.321 & 0.311 \\
Mean & $(0.0048)$ & $(0.0075)$ & $(0.0074)$ \\
& 747.0 & 740.3 & 754.2 \\
Yitzaki Relative Deprivation & $(6.82)$ & $(10.46)$ & $(11.45)$ \\
& 236.4 & 238.2 & 235.1 \\
& $(1.87)$ & $(2.63)$ & $(2.39)$ \\
\hline
\end{tabular}

Source: MHYS 2009-2010. Note: Bootstrapped standard errors in parentheses (100 repetitions) 
Table 4 - Relative Income Deprivation with Different Reference Groups

\begin{tabular}{ccc}
\hline & $\begin{array}{c}\text { Relative } \\
\text { Deprivation } \\
\text { (All) }\end{array}$ & $\begin{array}{c}\text { Relative } \\
\text { Deprivation } \\
\text { (Youth) }\end{array}$ \\
\hline When reference group is the population & & \\
Society & 0.157 & 0.140 \\
Female & $(0.0013)$ & $(0.0020)$ \\
Male & 0.076 & 0.071 \\
& $(0.0009)$ & $(0.0015)$ \\
When reference group is gender specific & 0.081 & 0.069 \\
Society & $(0.0009)$ & $(0.0014)$ \\
& & \\
Female & 0.128 & 0.106 \\
Male & $(0.0015)$ & $(0.0018)$ \\
& 0.160 & 0.134 \\
& $(0.0018)$ & $(0.0033)$ \\
\end{tabular}

Source: MHYS 2009-2010. Note: Bootstrapped standard errors in parentheses (100 repetitions) 
Table 5: Descriptive statistics

\begin{tabular}{lllllll}
\hline & \multicolumn{3}{c}{$\begin{array}{c}\text { Entire population } \\
\text { (aged 15-64) }\end{array}$} & \multicolumn{3}{c}{$\begin{array}{c}\text { Youth population } \\
\text { (aged 15-29) }\end{array}$} \\
& All & Males & Females & All & Males & Females \\
\hline Observations & 6451 & 3112 & 3339 & 2429 & 1169 & 1260 \\
Population share & 100 & 48.78 & 51.22 & 100 & 47.76 & 52.24 \\
Share employed & 40.2 & 70.6 & 11.3 & 33.8 & 59.7 & 10.1 \\
Share not employed & 59.8 & 29.4 & 88.7 & 66.2 & 40.3 & 89.9 \\
Unemployment rate & 13.9 & 12.1 & 23.2 & 23.9 & 21.3 & 35.5 \\
Education shares & & & & & & \\
$\quad$ No education & 42.3 & 29.8 & 54.2 & 24.2 & 14.1 & 33.5 \\
$\quad$ Primary education & 29.3 & 35.1 & 23.7 & 37.8 & 40.9 & 35.0 \\
$\quad$ Low secondary education & 15.1 & 18.7 & 11.7 & 24.0 & 29.4 & 19.0 \\
$\quad$ Secondary education & 9.0 & 11.5 & 6.6 & 9.9 & 11.6 & 8.3 \\
$\quad$ Tertiary education & 4.3 & 4.8 & 3.8 & 4.1 & 4.0 & 4.2 \\
$\quad$ Total & 100 & 100 & 100 & 100 & 100 & 100 \\
Married population share & 56.4 & 53.8 & 58.9 & 25.4 & 13.5 & 36.4 \\
Average Age & 35.7 & 36.2 & 35.2 & 22.6 & 22.8 & 22.4 \\
Urban population share & 53.3 & 53.5 & 53.1 & 46.3 & 48.0 & 44.7 \\
\hline Source: MHYS 2009-2010. & Nor & &
\end{tabular}

Source: MHYS 2009-2010. Note: For population aged 15 to 64 years currently not in school. 
Table 6: Probit regressions for estimating employment

\begin{tabular}{|c|c|c|c|c|}
\hline \multirow{2}{*}{$\begin{array}{l}\text { Dependent variable: Employed }=1 \text {; } \\
\text { not employed }=0\end{array}$} & \multicolumn{2}{|c|}{ All individuals } & \multirow{2}{*}{$\begin{array}{c}\text { Males } \\
(3)\end{array}$} & \multirow{2}{*}{$\begin{array}{c}\text { Females } \\
(4)\end{array}$} \\
\hline & (1) & (2) & & \\
\hline Primary education & $\begin{array}{l}0.0748 * * * \\
(0.0193)\end{array}$ & $\begin{array}{l}0.249 * * * \\
(0.0162)\end{array}$ & $\begin{array}{l}0.0551 * * \\
(0.0214)\end{array}$ & $\begin{array}{l}0.00602 \\
(0.0150)\end{array}$ \\
\hline Low secondary education & $\begin{array}{l}0.0523 * * \\
(0.0241)\end{array}$ & $\begin{array}{l}0.247 * * * \\
(0.0205)\end{array}$ & $\begin{array}{l}-0.0148 \\
(0.0268)\end{array}$ & $\begin{array}{l}0.0778 * * * \\
(0.0244)\end{array}$ \\
\hline Secondary education & $\begin{array}{l}0.100 * * * \\
(0.0275)\end{array}$ & $\begin{array}{l}0.280 * * * \\
(0.0228)\end{array}$ & $\begin{array}{l}-0.0129 \\
(0.0303)\end{array}$ & $\begin{array}{l}0.160 * * * \\
(0.0329)\end{array}$ \\
\hline Tertiary education & $\begin{array}{l}0.301 * * * \\
(0.0341)\end{array}$ & $\begin{array}{l}0.386 * * * \\
(0.0258)\end{array}$ & $\begin{array}{l}0.0789 * * \\
(0.0342)\end{array}$ & $\begin{array}{l}0.330 * * * \\
(0.0489)\end{array}$ \\
\hline Married & $\begin{array}{c}0.0256 \\
(0.0177)\end{array}$ & $\begin{array}{l}-0.00215 \\
(0.0155)\end{array}$ & $\begin{array}{l}0.308 * * * \\
(0.0242)\end{array}$ & $\begin{array}{l}-0.113 * * * \\
(0.0130)\end{array}$ \\
\hline Age & $\begin{array}{l}0.0476 * * * \\
(0.00366)\end{array}$ & $\begin{array}{l}0.0416 * * * \\
(0.00326)\end{array}$ & $\begin{array}{l}0.0422 * * * \\
(0.00403)\end{array}$ & $\begin{array}{l}0.0169^{* * * *} \\
(0.00270)\end{array}$ \\
\hline Age squared & $\begin{array}{c}-0.000576^{* * *} \\
(4.55 \mathrm{e}-05)\end{array}$ & $\begin{array}{c}-0.000459 * * * \\
(4.06 \mathrm{e}-05)\end{array}$ & $\begin{array}{c}-0.000599 * * * \\
(4.93 \mathrm{e}-05)\end{array}$ & $\begin{array}{c}-0.000187 * * * \\
(3.40 \mathrm{e}-05)\end{array}$ \\
\hline Urban & $\begin{array}{c}-0.0818 * * * \\
(0.0170)\end{array}$ & $\begin{array}{c}-0.118 * * * \\
(0.0150)\end{array}$ & $\begin{array}{c}-0.105^{* * *} \\
(0.0187)\end{array}$ & $\begin{array}{l}-0.00689 \\
(0.0130)\end{array}$ \\
\hline Male & $\begin{array}{c}0.601 * * * \\
(0.0106)\end{array}$ & & & \\
\hline Region dummies & Yes & Yes & Yes & Yes \\
\hline Observations & 6,451 & 6,451 & 3112 & 3339 \\
\hline Pseudo R2 & 0.33 & 0.07 & 0.15 & 0.15 \\
\hline
\end{tabular}

Source: MHYS 2009-2010. Note: Marginal effects, evaluated at sample means for continuous variables, are shown. Robust standard errors in parentheses: $* * * \mathrm{p}<0.01, * * \mathrm{p}<0.05, * \mathrm{p}<0.1$. 
Table 7: Relative Labor Deprivation

RLD (All)

When the reference group is the population

Society

Female

Male

When reference group is gender specific Society

Female

Male
0.279

(0.0027)

0.202

(0.0014)

0.077

(0.0017)

0.240

(.0026)

$-0.137$

0.0015

0.292

(0.0063)
RLD (Youth)

0.269

(0.0043)

0.179

(0.0024)

0.090

(0.0034)

0.221

(0.0037)

0.118

(0.0025)

0.291

(0.0081)

Source: MHYS 2009-2010. Note: Bootstrapped standard errors in parentheses (100 repetitions) 
Figure 1 - Lorenz curves of individual relative labor deprivation $\left(R L D_{i}\right)$
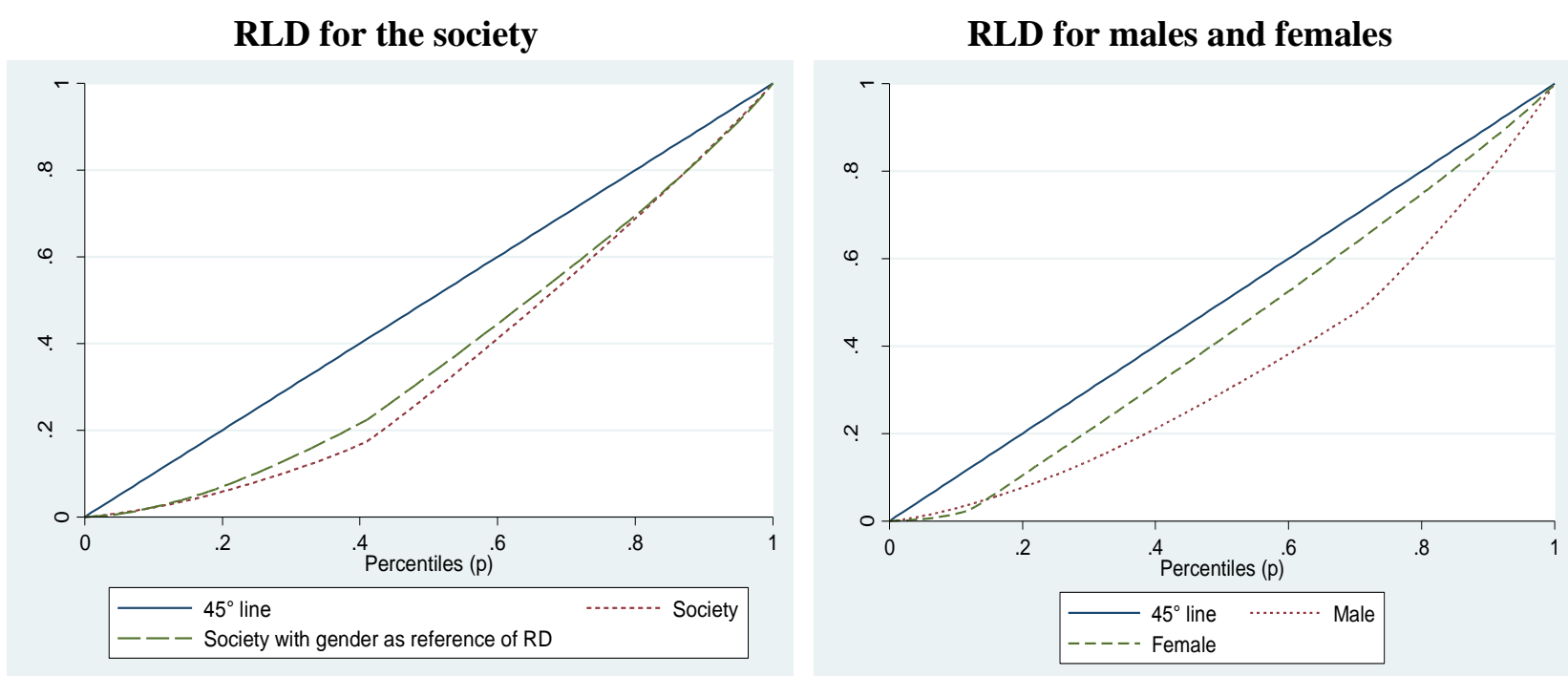

Source: MHYS 2009-2010. 
Table 8: Ordered Probit regressions of determinants of young people's (aged 15-29) satisfaction with opportunities to improve one's social status in the future ${ }^{8}$

\begin{tabular}{|c|c|c|c|c|}
\hline \multirow{2}{*}{$\begin{array}{l}\text { Dependent Variable: 1= highly dissatisfied; } \\
\text { 2=dissatisfied; 3=satisfied; 4= highly satisfied }\end{array}$} & \multicolumn{2}{|c|}{ All individuals } & \multirow{2}{*}{$\begin{array}{c}\text { Females } \\
(3)\end{array}$} & \multirow{2}{*}{$\begin{array}{c}\text { Males } \\
(4)\end{array}$} \\
\hline & (1) & (2) & & \\
\hline Employed & $\begin{array}{l}0.324 * * * \\
(0.0639)\end{array}$ & & & \\
\hline $\begin{array}{l}\text { Individual Relative Labor Deprivation } \\
\text { (reference: all individuals) }\end{array}$ & & $\begin{array}{l}-5,465 * * * \\
(968.4)\end{array}$ & & \\
\hline $\begin{array}{l}\text { Individual Relative Labor Deprivation } \\
\text { (reference: individuals of same gender) }\end{array}$ & & & $\begin{array}{c}-3,280 * * \\
(1,597)\end{array}$ & $\begin{array}{c}-1,964 * * * \\
(352.3)\end{array}$ \\
\hline Primary education & $\begin{array}{c}0.0987 \\
(0.0687)\end{array}$ & $\begin{array}{c}0.182 * * * \\
(0.0696)\end{array}$ & $\begin{array}{c}0.140 \\
(0.0874)\end{array}$ & $\begin{array}{l}0.0920 \\
(0.120)\end{array}$ \\
\hline Low secondary education & $\begin{array}{c}0.217 * * * \\
(0.0770)\end{array}$ & $\begin{array}{c}0.297 * * * \\
(0.0781)\end{array}$ & $\begin{array}{l}0.145 \\
(0.104)\end{array}$ & $\begin{array}{c}0.300^{* *} \\
(0.126)\end{array}$ \\
\hline Secondary education & $\begin{array}{c}0.339 * * * \\
(0.0955)\end{array}$ & $\begin{array}{l}0.431 * * * \\
(0.0966)\end{array}$ & $\begin{array}{l}0.418 * * * \\
(0.139)\end{array}$ & $\begin{array}{c}0.360 * * \\
(0.150)\end{array}$ \\
\hline Tertiary education & $\begin{array}{c}0.600 * * * \\
(0.137)\end{array}$ & $\begin{array}{c}0.749 * * * \\
(0.137)\end{array}$ & $\begin{array}{c}0.741 * * * \\
(0.193)\end{array}$ & $\begin{array}{c}0.759 * * * \\
(0.208)\end{array}$ \\
\hline Married & $\begin{array}{c}0.317 * * * \\
(0.0609)\end{array}$ & $\begin{array}{l}0.317 * * * \\
(0.0609)\end{array}$ & $\begin{array}{l}0.393 * * * \\
(0.0758)\end{array}$ & $\begin{array}{l}0.0886 \\
(0.113)\end{array}$ \\
\hline Youth aged (20-24) & $\begin{array}{l}0.00640 \\
(0.0658)\end{array}$ & $\begin{array}{c}0.0439 \\
(0.0656)\end{array}$ & $\begin{array}{l}-0.119 \\
(0.0896)\end{array}$ & $\begin{array}{c}0.164 \\
(0.100)\end{array}$ \\
\hline Youth aged (25-29) & $\begin{array}{l}-0.0541 \\
(0.0708)\end{array}$ & $\begin{array}{c}0.0136 \\
(0.0701)\end{array}$ & $\begin{array}{l}-0.0966 \\
(0.0982)\end{array}$ & $\begin{array}{l}0.0542 \\
(0.105)\end{array}$ \\
\hline Urban & $\begin{array}{c}0.258 * * * \\
(0.0581)\end{array}$ & $\begin{array}{c}0.220 * * * \\
(0.0583)\end{array}$ & $\begin{array}{l}0.332 * * * \\
(0.0815)\end{array}$ & $\begin{array}{c}0.157^{*} \\
(0.0867)\end{array}$ \\
\hline Male & $\begin{array}{l}-0.156^{* *} \\
(0.0619)\end{array}$ & $\begin{array}{l}-0.169 * * * \\
(0.0614)\end{array}$ & & \\
\hline $\begin{array}{l}\text { Region dummies } \\
\text { Constant }\end{array}$ & Yes & Yes & Yes & Yes \\
\hline cut 1 & $\begin{array}{l}-0.0574 \\
(0.184)\end{array}$ & $\begin{array}{l}-0.283 \\
(0.189)\end{array}$ & $\begin{array}{l}-0.129 \\
(0.224)\end{array}$ & $\begin{array}{l}-0.436 \\
(0.355)\end{array}$ \\
\hline cut2 & $\begin{array}{c}0.843 * * * \\
(0.184)\end{array}$ & $\begin{array}{c}0.619 * * * \\
(0.190)\end{array}$ & $\begin{array}{c}0.802 * * * \\
(0.225)\end{array}$ & $\begin{array}{c}0.485 \\
(0.356)\end{array}$ \\
\hline cut3 & $\begin{array}{c}1.719 * * * \\
(0.187)\end{array}$ & $\begin{array}{c}1.497 * * * \\
(0.192)\end{array}$ & $\begin{array}{c}1.759 * * * \\
(0.229)\end{array}$ & $\begin{array}{c}1.322 * * * \\
(0.357)\end{array}$ \\
\hline Observations & 2,128 & 2,128 & 1,155 & 973 \\
\hline Pseudo R2 & 0.0463 & 0.0476 & 0.0513 & 0.0820 \\
\hline
\end{tabular}

Note: Robust standard errors in parentheses; *** $\mathrm{p}<0.01, * * \mathrm{p}<0.05, * \mathrm{p}<0.1$; The reference groups is rural unmarried youth aged 15-19 without any education (for model 1 and 2 add female).

\footnotetext{
${ }^{8}$ Some of the variables used in Table 8 are the same variables used in the probit equation in Table 6 . This can potentially cause multicollinearity and endogeneity. However, this is not uncommon in two-steps models. In fact, Elbers et al. (2005) showed that in two-steps models the statistics calculated from expected values can actually be used in subsequent research, either as a dependent or as an independent variable in models where the original first-step variables are also used. Tests for multicollinearity indicated no evidence of multicollinearity in our data. The variance inflation factor (v.i.f.) for the relative deprivation variable was lower than 1.5 for different model specifications.
} 
Table 9: Probit estimates of determinants of young people's (aged 15-29) wish to migrate abroad

\begin{tabular}{|c|c|c|c|c|}
\hline \multirow[t]{2}{*}{ Dependent variable: $\mathrm{Yes}=1 ; \mathrm{No}=0$} & \multicolumn{2}{|c|}{ All individuals } & \multirow{2}{*}{$\begin{array}{c}\text { Females } \\
(3)\end{array}$} & \multirow{2}{*}{$\begin{array}{c}\text { Males } \\
(4)\end{array}$} \\
\hline & $(1)$ & $(2)$ & & \\
\hline Employed & $\begin{array}{l}-0.0236 \\
(0.0243)\end{array}$ & & & \\
\hline $\begin{array}{l}\text { Relative Labor Deprivation (reference: all } \\
\text { individuals) }\end{array}$ & & $\begin{array}{c}386.5 \\
(377.3)\end{array}$ & & \\
\hline $\begin{array}{l}\text { Relative Labor Deprivation (reference: } \\
\text { individuals of same gender) }\end{array}$ & & & $\begin{array}{l}-276.6 \\
(439.2)\end{array}$ & $\begin{array}{c}400.7 * * * \\
(154.6)\end{array}$ \\
\hline Primary education & $\begin{array}{c}0.0125 \\
(0.0301)\end{array}$ & $\begin{array}{l}0.00723 \\
(0.0302)\end{array}$ & $\begin{array}{l}-0.0202 \\
(0.0286)\end{array}$ & $\begin{array}{c}0.0666 \\
(0.0534)\end{array}$ \\
\hline Low secondary education & $\begin{array}{c}0.0937 * * * \\
(0.0349)\end{array}$ & $\begin{array}{c}0.0884 * * \\
(0.0352)\end{array}$ & $\begin{array}{c}0.0800 * * \\
(0.0395)\end{array}$ & $\begin{array}{l}0.128 * * \\
(0.0562)\end{array}$ \\
\hline Secondary education & $\begin{array}{l}0.0778^{*} \\
(0.0432)\end{array}$ & $\begin{array}{c}0.0713 \\
(0.0434)\end{array}$ & $\begin{array}{l}0.132 * * \\
(0.0594)\end{array}$ & $\begin{array}{c}0.0683 \\
(0.0681)\end{array}$ \\
\hline Tertiary education & $\begin{array}{c}0.0692 \\
(0.0632)\end{array}$ & $\begin{array}{c}0.0584 \\
(0.0625)\end{array}$ & $\begin{array}{c}0.0517 \\
(0.0696)\end{array}$ & $\begin{array}{c}0.0987 \\
(0.0960)\end{array}$ \\
\hline Married & $\begin{array}{c}-0.148 * * * \\
(0.0229)\end{array}$ & $\begin{array}{c}-0.147 * * * \\
(0.0229)\end{array}$ & $\begin{array}{c}-0.0790 * * * \\
(0.0222)\end{array}$ & $\begin{array}{c}-0.224 * * * \\
(0.0475)\end{array}$ \\
\hline Youth aged (20-24) & $\begin{array}{l}0.00895 \\
(0.0270)\end{array}$ & $\begin{array}{l}0.00640 \\
(0.0268)\end{array}$ & $\begin{array}{l}0.00664 \\
(0.0279)\end{array}$ & $\begin{array}{c}0.0141 \\
(0.0444)\end{array}$ \\
\hline Youth aged (25-29) & $\begin{array}{l}-0.0283 \\
(0.0284)\end{array}$ & $\begin{array}{l}-0.0329 \\
(0.0279)\end{array}$ & $\begin{array}{l}-0.0250 \\
(0.0294)\end{array}$ & $\begin{array}{c}-0.00942 \\
(0.0467)\end{array}$ \\
\hline Urban & $\begin{array}{c}0.0837 * * * \\
(0.0239)\end{array}$ & $\begin{array}{c}0.0863 * * * \\
(0.0240)\end{array}$ & $\begin{array}{l}0.0531^{*} \\
(0.0272)\end{array}$ & $\begin{array}{c}0.0919 * * \\
(0.0389)\end{array}$ \\
\hline Male & $\begin{array}{c}0.321 * * * \\
(0.0237)\end{array}$ & $\begin{array}{c}0.322 * * * \\
-0.0235\end{array}$ & & \\
\hline Region dummies & Yes & Yes & Yes & Yes \\
\hline Observations & 2,128 & 2,128 & 1,085 & 973 \\
\hline Pseudo R2 & 0.176 & 0.176 & 0.0905 & 0.0907 \\
\hline
\end{tabular}

Note: Marginal effects, evaluated at sample means for continuous variables, are shown. Robust standard errors in parentheses: $* * * \mathrm{p}<0.01, * * \mathrm{p}<0.05, * \mathrm{p}<0.1$. The reference groups is rural unmarried youth aged 15-19 without any education (for model 1 and 2 add female) 